\title{
LA CREACION DE GRUPOS PARLAMENTARIOS DURANTE LA LEGISLATURA
}

POR

MANUEL ALBA NAVARRO

Letrado de las Cortes Generales

SUMARIO

I. Introducción.-II. Vertiente JURÍdica del PROBlema: El derecbo de constituir grupos parlamentarios: a) La titularidad del derecho a crear grupos parlamentarios: el artículo 20.1 del RPC. b) Los límites temporales del ejercicio del derecho. Planteamiento general.-III. VERTIENTE POLÍTICA DEL PROBLEMA: a) Diputado individual y cambios de grupos. b) El mandato representativo. El artículo 67.2 de la Constitución.-IV. ULTIMAS OBSERVACIONES.

\section{INTRODUCCION}

Hace muy pocas fechas, el prólogo de un profesor español a un libro propio volvía a poner sobre el tapete uno de los temas que más han preocupado a los juristas teóricos y también a los prácticos a la hora de abordar el estudio del Derecho, y, más en concreto, el sector del Derecho constitucional ${ }^{1}$. Este tema es el de la interrelación que existe, ha existido y existirá entre el mundo de lo jurídico y el de lo político y la tentativa, pertinaz pero frecuentemente baldía, de marcar líneas profundas de distinción entre uno y otro sector.

Creemos necesario hacer este breve recordatorio porque uno de los argumentos fundamentales que se han utilizado a la hora de abordar el problema que nos ocupa es el de que se trataba de una cuestión política que no debía sujetarse a un marco de resolución jurídico o, cuando menos, no en sus líneas fundamentales.

Ciertamente que, como señaló con su habitual agudeza G. Jellinek, «... todo el proceso de la vida del Estado, todos los principios de su orden jurídico, fueron antes de nacer objeto de reflexiones políticas; todo acto realizado por

1 Nos referimos al prólogo de E. García de Enterría a su libro La Constitución como norma y el Tribunal Constitucional, Madrid, 1981. 
el Estado, todo derecho que se afirma, produce efectos políticos» ${ }^{2}$. El intento de captar desde un punto de vista formalista y aséptico los fenómenos del Derecho constitucional, de intentar eludir la realidad en la que se enmarcan su creación, vida y extinción es, cuando menos, acientífica, si lo que se pretende es dar una visión coherente y correcta del porqué de los fenómenos y de su funcionamiento. A nadie se le escapa que «una proposición de Derecho político que formalmente no haya cambiado puede, no obstante, a causa de las fuerzas políticas, lograr que el contenido sea completamente distinto» ${ }^{3}$.

Ello es también cierto si se intenta aislar por un procedimiento químico de separación el Derecho constitucional y el substrato histórico que le sirve de base. Todo análisis ahistórico de la realidad jurídica —sin que ello implique necesariamente caer en un trasnochado «historicismo total»- está desprovisto de basamento y, por formular mal sus premisas metodológicas, condenado a llegar a conclusiones erróneas ${ }^{4}$.

Pero siendo esto absolutamente correcto, no lo es menos que, como ha puesto de relieve el propio García Pelayo ${ }^{5}$, «conviene distinguir -aunque no separar - la dimensión jurídica de la constitución de otras de sus dimensiones posibles. En el primer aspecto, y cualquiera que sea la modalidad específica de su realización, las normas jurídicas constitucionales tienen la función de racionalizar, de normalizar, de disciplinar, de sustentar sobre marcos de referencia ciertos la convivencia política de un pueblo...». Pues bien, «dentro de - este ámbito normativo -indica el mismo autor-, la constitución tiene su propio logos, su propia dialéctica de naturaleza jurídica, y, en este sentido, se configura como un sistema autónomo».

Si aceptamos el encuadre de los Reglamentos parlamentarios dentro de la «constitución en sentido material» de la que habla la doctrina italiana, creemos que las reflexiones anteriores acerca del Derecho constitucional y de sus normas son absolutamente aplicables al caso que nos ocupa: esto es, a la (im)posibilidad de crear grupos parlamentarios en el transcurso de la legislatura.

De acuerdo con lo que hemos dejado entrever, pienso que, como decía Nicolás Pérez Serrano, lejos de intentar trazar aristas agudas y tajantes donde la realidad presenta un compuesto multiforme y abigarrado ${ }^{6}$, lo que se puede formular es un intento de separación de las vías de aproximación o de estudio (el approach del que habla la doctrina anglosajona) de un fenómeno que, efectivamente, integra en su seno componentes de muy diversa índole. Es siguiendo esta vía donde plantearemos, en primer lugar, un enfoque jurídico del problema, para dar a continuación -y en la medida en que no estén ya solventadas con anterioridad- las explicaciones de índole política que sustenten, expliquen y llenen de sentido a la estructura jurídico-reglamentaria previa.

${ }^{2}$ Cfr. G. Jellinek, Teoría general del Estado, Buenos Aires, 1973, pág. 12.

${ }^{3}$ Cfr. Jellinek, op. cit., pág. 13.

${ }^{4}$ En este sentido véase M. García Pelayo, Las transformaciones del Estado contemporáneo, Madrid, 1977, pág. 130.

${ }^{5}$ Op. cit., pág. 131.

- N. Pérez Serrano, Tratado de Derecbo político, Madrid, 1976, págs. 47 y sigs. 


\section{VERTIENTE JURIDICA DEL PROBLEMA}

Como sucede muchas veces en el ámbito de lo jurídico, los grupos parlamentarios (de los que no se trata en el presente artículo de hacer una teoría general) son regulados jurídicamente con posterioridad a su aparición como dato fáctico en el mundo de las Asambleas legislativas ${ }^{7}$.

Pero no se regulan siempre de manera idéntica, sino en cada caso teniendo en cuenta las peculiaridades del modelo político y parlamentario en el que van a jugar dichos grupos. Por ello tiene especial importancia observar cómo se norma en cada caso la constitución de los mismos, y por ello también nos vamos a detener ahora en concréto en el sistema establecido en el artículo 20 del Reglamento Provisional del Congreso, uno de los dos artículos que componen el título III («De los grupos parlamentarios») de dicho cuerpo normativo.

\section{El derecbo de constituir grupos parlamentarios}

En primer lugar hay que acotar jurídicamente un esquema conceptual que nos permita interpretar el fenómeno de la constitución de los grupos parlamentarios. A nuestro juicio, el grupo parlamentario -y en ello se insistirá a lo largo del presente artículo - es el centro de tensión de dos necesidades: por un lado, la necesidad de articulación de una estructura operativa, parlamentariamente hablando, por parte de los miembros de un partido político o coalición electoral (con la salvedad del Grupo Mixto); por otra, la absoluta exigencia que siente la Cámara de dotarse de una organización que la haga funcional y adecuada en sus mecanismos al alto servicio que tiene que cumplir.

Estas son las líneas maestras que nos deben servir para interpretar la regulación que los Reglamentos parlamentarios, y en este caso el Provisional del Congreso, hácen de los grupos parlamentarios.

Dentro de ese esquema conceptual-jurídico del que antes hablaba, me parece especialmente útil recurrir, a la hora de explicar la constitución de grupos parlamentarios, a la figura del derecho subjetivo. Como el derecho subjetivo, stricto sensu, la constitución de grupos está ligada a una serie de presupuestos adquisitivos de los mismos; como el derecho subjetivo, una vez aparecido en la escena jurídica deriva una serie de efectos y consecuencias que se. despliegan esencialmente en facultades. Cierto que esta equiparación requeriría ciertas matizạciones en cuanto que, dado el peculiar sector del ordenamiento en el que se incardina el problema que estamos abordando, su trasplante, sin precisiones ulteriores, podría originar algunos trastornos y malentendidos, pero no menos cierto que la tan acunada figura del derecho subjetivo encuadra perfectamente en la necesidad de explicar su constitución.

${ }^{7}$ Véase a este respecto y pára el caso francés el artículo de J. Waline «Les groupes parlementaires en France», en Rev. de Droit Publique et de la Science Politique, 1961, que señala cómo, a despecho de varias prohibiciones expresas, los grupos reaparecían constantemente en la práctica. 
Hablando en términos generales de los derechos, cabe reseñar que éstos se clasifican esencialmente atendiendo tanto al sujeto detentador o titular de los mismos como, positivamente, por el contenido de los propios derechos (que diferencia unos de otros), y, negativamente, por el tenor de los límites y limitaciones que acotan el derecho y, correlativamente, marcan su contorno (tema este, por cierto, de gran controversia en la doctrina jurídico-administrativa española). Los derechos no son abstractos e incondicionados y por ello el tema de los límites es un tema capital.

Dando por supuesto que el contenido de los derechos de los grupos parlamentarios se halla diseminado por todo el Reglamento (así, por ejemplo, art. 21: «locales y medios materiales suficientes»; art. 27: «asistencia a la junta de portavoces; derecho a la presentación de mociones»: art. 138, etc.) y no es susceptible de especial confusión, sí que es conveniente, por el contrario, fijarse en la cuestión que suscita tanto la titularidad del derecho a constituir grupos parlamentarios como el problema de los límites que marcan sus contornos.

\section{a) La titularidad del derecho a crear grupos parlamentarios: el artículo 20.1 del RPC}

Es precisamente el primer inciso del primer apartado del primer artículo el que se ocupa de determinar quiénes pueden constituir grupos parlamentarios y con qué requisitos. Dispone, en efecto, el artículo 20.1, en su primer inciso, que:

«Podrán constituirse en grupos parlamentarios las formaciones políticas o coaliciones electorales que cuenten al menos con cinco diputados.»

Dejando ahora de lado el tema del número mínimo exigido por el Reglamento para poder constituir grupos parlamentarios, número que siempre es objeto de ácidos debates cuando llega la hora de su regulación en las distintas Asambleas parlamentarias, y sin olvidar que el segundo párrafo de este mismo artículo 20.1 señala la prohibición para los diputados de pertenecer simultáneamente a más de un grupo, creemos que el tema que debe centrar nuestra atención es el de pergeñar los conceptos de formación política y coalición electoral.

Y ello es especialmente importante si tenemos en cuenta que la redacción última del artículo 20.1 del RPC, adoptada en la sesión plenaria del Congreso del día 3 de mayo de 1979, se opone frontalmente a la antigua formulación de este precepto, que, en su redacción originaria, sostenía otro tenor ${ }^{8}$. En efecto, frente a una mera constatación de que los grupos parlamentarios deberían constar al menos de quince diputados y la posibilidad, a pesar de ello, de formar grupos parlamentarios que se otorgaba a ciertos diputados en determinados

${ }^{8}$ Véase Reglamento Provisional del Congreso, edición de las Cortes Generales, pág. 20, nota 1 . 
casos, la dicción que antes recogimos del artículo 20.1 del RPC, tras su modificación, dictamina tajantemente que la posibilidad de constituir grupos parlamentarios les corresponde a «las formaciones políticas o coaliciones electorales», siempre y cuando cuenten al menos con cinco diputados.

A mi juicio, visto el encaje sistemático del concepto formación política, su utilización reiterada en las Resoluciones de la Presidencia sobre designación de la Comisión de Incompatibilidades de 28 de marzo de $1979^{9}$, y sobre ponderación de voto en las votaciones de las Comisiones de 27 de abril de $1979^{10}$, por formación política hay que entender partido político.

Por ende, la primera nota que habría que resaltar es que, contrariamente a lo que se prevé en numerosos Reglamentos extranjeros y a lo que se puede observar en el propio Reglamento actual del Congreso tras de su aprobación el 10 de febrero de $1982^{11}$, los entes que se hallan capacitados para constituir grupos parlamentarios son los partidos políticos y las coaliciones electorales, debiendo sujetarse los primeros a lo previsto en la Ley 54/1978, de 4 de diciembre, de partidos políticos, y remitiéndose los segundos —aun habida cuenta de las justificadas dudas que hay sobre la vigencia actual de esta norma- a lo preceptuado en los artículos 30 y sigs. del Real Decreto-Ley 20/ 1977 , de 18 de marzo, sobre normas electorales.

De todo lo cual se desprende claramente que en la configuración del RPC, la titularidad no radica nunca en los diputados, aislada o conjuntamente, sino en los partidos/formaciones políticos/as y en las coaliciones electorales, siempre y cuando tengan, además, cinco diputados.

Una vez determinado esto, cabe, a nuestro juicio, señalar dos vías de análisis que permiten explicar esta atribución a dichos entes, y que pone de relieve Mortati cuando, al estudiar la posición de los miembros del Parlamento, señala que: «la posizione giuridica rivestita dai membri del Parlamento non può essere essattamente interpretata se non si tenga in conto dei molteplici rapporti in cui essi vengono a trovarsi in ragione, da una parte della loro derivazione dal corpo elettorale e della appartenenza ai partiti pel cui tramite si fanno valere le scelte popolari, e dall'altra della loro qualità di membri del Supremo organo costituzionale, cui è demandata la determinazione delle linee direttive della politica nazionale» ${ }^{12}$.

1. La primera línea argumental que explica la conexión es la intima vinculación que existe entre partido político y grupo parlamentario ${ }^{13}$. No se

9 BOC de 29 de marzo de 1979.

10 BOC de 2 de mayo de 1979

"BOC de 24 de febrero de 1982.

${ }^{12}$ Cfr. C. Mortati, Istituzioni di Diritto Pubblico, Padua, 1975 (9. edición), pág. 486.

${ }^{13}$ Véase en este sentido la opinión prácticamente unánime de los autores. Así, por ejemplo, Savignano, en su obra I Gruppi Parlamentari (Nápoles, 1965), señala que «I gruppi parlamentari debbono corrispondere in ogni caso a gruppi politici preesistenti di modo che va escluso che possano formarsi gruppi parlamentari sulla base di un altro criterio" (pág. 57). En el mismo autor y obra, véase también, corroborando esta aserción, las páginas 39 y 196, donde dice con toda exactitud que «Il ruolo assunto dai gruppi parlamentari all'interno delle assemblea legislative non puo esattamente comprendersi, e tanto meno giustificarsi, se non si chiarisce, cogliendono gli aspetti esserziali, il collegamento che intercorre tra $i$ gruppi stessi ed $i$ partiti politicir. En idéntico sentido se manifiesta Waline al definir primariamente el grupo como «la représentation du parti politique sur le plan par- 
trata ahora, ni es éste el momento oportuno, de hacer un estudio de la naturaleza jurídica del grupo parlamentario y de su configuración a caballo entre el partido que le sustenta y el Parlamento donde desarrolla sus labores, pero no es menos cierto que, como dice el propio Waline, «en fait, le groupe parlementaire se situe presque toujours dans un ensemble beaucoup plus vaste dont il ne constitue qu'un rouage: le parti politique. Pour comprendre l'organisation des groupes parlementaires il faut avoir présent à l'esprit ce lieu qui existe presque toujours entre le groupe parlementaire et un parti politique» ${ }^{14}$.

Y esto es así no sólo desde un punto de vista meramente teórico o en la pura praxis, sino más aún en la configuración que de los grupos hacen los distintos Reglamentos. Para el caso italiano, señala Rossano que «va altresi considerato che il principio della sostanziale corrispondenza dei gruppi parlamentari a partiti politici trova conferma nella norma del Regolamento della Camera dei Deputati (art. 14, comma 2)...» ${ }^{15}$. Para el caso alemán, baste señalar que el artículo 10 del Reglamento del Bundestag define a los grupos (Fraktionen) como agrupación de miembros del Bundestag que pertenecen al mismo partido.

Con independencia de las múltiples teorías sobre la naturaleza jurídica de los grupos parlamentarios, parece unánime en la doctrina la posición de remarcar que, con la excepción del Grupo Mixto (del que nos proponemos ocuparnos en su día), la característica esencial de los mismos es su vinculación a los partidos políticos, aunque sin confundirse con ellos obviamente. $\mathrm{La}$ atribución de la titularidad de la creación de grupos parlamentarios a las «formaciones políticas o coaliciones electorales» encuentra, pues, por un lado, su justificación en la primacía dada al partido en los modernos ordenamientos, y que más tarde trataremos en detalle en su vertiente política.

2. Existe un segundo fenómeno nada despreciable a la hora de intentar explicar argumentalmente la atribución de la titularidad de creación de grupos parlamentarios a los partidos políticos y coaliciones electorales. Este fenómeno es el de la indudable conexión existente entre el fenómeno electoral y la formación de grupos parlamentarios.

No se trata ya sólo, como dice Rescigno, de que «il gruppo giuridicamente cessa con il cessare delle Camere (o, più correttamente, con il cessare dei parlamentari, poiche le Camere como organi sono permanenti) e quindi, in forza della prorogatio, cessa non al momento dello scioglimento ma al momento delle nuove elezioni» ${ }^{16}$, sino de que son los partidos políticos y las coaliciones electorales los que se presentan ante el electorado y los que, consiguientemente, pueden reflejar su estructura política en grupos parlamentarios, siempre y cuando hayan obtenido el número mínimo de diputados requeridos por

lementaire», señalando la «... relation étroite qui existe entre le parti politique et son groupe parlementaire...» (véase ob. cit., pág. 1172). Asimismo es válida la referencia a Burdeau cuando define los grupos parlamentarios en sentido análogo al de Waline. Véase Droit constitutionnel et institutions politiques, París, 1959, pág. 458.

${ }_{14}$ Cfr. Waline, «Les Groupes...», cit., pág. 1206.

${ }^{15}$ Cfr. C. Rossano, Partiti e Parlamento nello stato contemporaneo, Nápoles, 1972, pág. 262.

is Véase G. U. Rescigno, voz «Gruppi Parlamentari», en Enciclopedia del Diritto, t. XIX, pág. 262. 
los preceptos reglamentarios. Las elecciones como articulación de dos elementos fundamentales: el pueblo en su forma de cuerpo electorál y los partidos políticos que proponen a los candidatos ${ }^{17}$, son las que diseñan un mapa y una voluntad política que, en la medida de lo posible, deben ser respetados y articulados en el Parlamento.

No olvidemos, por otra parte, que una de las causas básicas de consolidación del régimen de grupos parlamentarios fue la implantación del sistema electoral proporcional y de listas cerradas y bloqueadas que proporcionaba a los partidos políticos mayores facultades a la hora de configurar la voluntad del electorado ${ }^{18}$, y que, por cierto, es el que rige en nuestro país merced a la regulación efectuada por el antes citado Real Decreto-Ley 20/1977, de 18 de marzo, en sus artículos 20 y sigs. Es éste un dato que no debe dejarse caer en el olvido, porque la pertenencia a un partido político y el deseo manifestado por el cuerpo electoral no condicionan de hecho sólo la elección del parlamentario, sino que se reflejan también en el interior de las Cámaras, obligando - al menos moralmente- a los diputados al respeto de las propuestas programáticas formuladas en el período electoral ${ }^{19}$.

Sin perjuicio de tratar más adelante la repercusión del régimen electoral sobre la configuración y entendimiento del mandato parlamentario, parece claro que, vinculando la creación de grupos parlamentarios a las formaciones políticas y coaliciones electorales, se logra la articulación parlamentaria en grupos parlamentarios de las opciones electorales emanadas de la voluntad popular.

\section{b) Los limites temporales del ejercicio del derecho. Planteamiento general}

Determinado, pues, el sujeto o ente titular del derecho de creación de grupos parlamentarios y explicitadas las razones que pueden ayudar a comprender el régimen jurídico-reglamentario implantado por el RPC, nos toca ahora abordar, siguiendo la sistemática que nos habíamos propuesto, los límites de este derecho.

No se puede considerar propiamente como límite la necesidad de que la formación política o coalición electoral cuente con cinco diputados, puesto que esto es más bien un requisito o presupuesto para acceder al derecho.

Por contra, sí tiene el carácter de límite el límite temporal a la creación de grupos parlamentarios.

Remitiéndonos en general a la teoría de los derechos subjetivos, se puede admitir con Díez-Picazo y Gullón que «los derechos subjetivos están con frecuencia sometidos a un límite temporal, que puede afectar a su existencia

${ }^{17}$ Cfr. Zanetti, Dalle stato liberale allo stato dei partiti - la rappresentanza politica, Milán, 1965, pág. 104.

${ }_{18}$ Sobre este tema véase Savignano, ob. cit., pág. 19; Rossano, op. cit., pág. 63, y Mortati, Istituzioni..., cit., pág. 490.

${ }_{19}$ Véase Savignano, ob. cit., pág. 205. No se nos escapa, no obstante, que la principal acusación que se suele cruzar en los casos de escisión interna de los partidos es precisamete el incumplimiento del programa electoral. 
misma o bien a la admisibilidad de los actos de ejercicio...» y también que «el tiempo puede operar como una condición o límite de los actos de ejercicio del derecho. El derecho subjetivo debe ejercitarse tempestivamente y en tiempo oportuno. Se considera intempestivo el ejercicio retrasado, que adopta dos formas básicas: la prescripción y la caducidad» ${ }^{20}$.

Sentado lo que antecede, ¿cuál es la solución que otorga nuestro Reglamento a este tema?

A nuestro juicio, ésta se halla contenida en el artículo 20.3 cuando dispone que:

"Los grupos parlamentarios se constituirán antes de la elección de la Mesa definitiva...»

Este precepto es el que, en realidad, centra el tema que nos ocupa. En efecto, se ha dicho que «esta circunstancia, no obstante, no debe significar que, con posterioridad a esos dos momentos iniciales (se hace referencia también al plazo de cinco días hábiles previsto en el artículo 13 del Reglamento Provisional del Senado), no sea posible constituir nuevos grupos parlamentarios... ${ }^{21}$; y en el mismo sentido, Torres del Moral, reseñando el artículo 15.3 del Reglamento del Senado italiano, que permite la constitución de nuevos grupos durante el transcurso de la legislatura, indica que, «... a mi juicio, esta posibilidad es de aplicación general, porque, del mismo modo que no se impiden los cambios de miembros de un grupo a otro, entendemos que el silencio reglamentario no veda la constitución de un nuevo grupo durante la legislatura...», y continúa: «... de hecho, así sucedió en Italia por escisión del PSIUP y PSI en 1964 y así ha sucedido en el Congreso español por la escisión del Grupo Minoría Vasco-Catalana en dos: Minotía Catalana y Grupo Vasco (PNV) ${ }^{22}$.

Del mismo parecer es Rescigno, que señala que «va infine notato che $i$ regolamenti delle Camere prevedono che $i$ gruppi si formino all'inizio della legislatura. La regola è ovvia. Giacchè, a tacer di ogni altro, i gruppi sono necessari per la costituzione delle commissioni permanenti, le quali, come parti strutturali di ciascuna camera, debbono essere costituite immediatamente. Proprio per questo pero è inesatto dedurre da questa regola che $\mathrm{i}$ gruppi possono costituirsi solo all'inizio della legislatura. Al contrario, l'esperienza dice e ressuna regola vieta che, in caso di scissione, si formi un nuovo gruppo parlamentare durante la legislatura (com'è avvenuto nel 1964 al momento della scissione del PSIUP dal PSI) ${ }^{23}$.

Frente a estas argumentaciones, respetables todas ellas, cabe objetar lo siguiente:

${ }^{20}$ Cfr. L. Díez-Picazo y A. Gullón, Sistema de Derecbo civil, vol. I, Madrid, 1975, pág. 434.

${ }_{21}$ Así, Linde Paniagua, «El grupo parlamentario de Acción Democrática», en el diario El País de 3 de enero de 1982.

22 Cfr. Torres del Moral, «Los grupos parlamentarios», en esta misma Revista de Derecbo Político, núm. 9, pág. 34.

${ }_{23}$ Cfr. Rescigno, ob. cit., pág. 783. 
1. En primer lugar, hay que negar de raíz que exista en modo alguno silencio o laguna reglamentaria respecto del tema que estamos tratando. El primer inciso del apartado 3 del artículo 20 del RPC es, a estos efectos, bastante esclarecedor: «Los grupos parlamentarios se constituirán antes de la elección de la Mesa definitiva...», y ante tan tajante aseveración no podemos admitir en modo alguno la hipótesis de una laguna reglamentaria. Lo contrario sería una interpretación incorrecta e inexacta de la dicción literal de un precepto que no deja dudas en su favor y, por ende, una contravención del artículo 3 del propio Código Civil.

2. Tampoco es admisible que la dicción del artículo 20.3 del RPC se interprete como una mera «posibilidad» (sic) de crear grupos parlamentarios en el momento anterior a la elección de la Mesa definitiva del Congreso ${ }^{24}$. Hemos visto antes que todos o casi todos los derechos y acciones que existen en el mundo del Derecho tienen unos plazos y límites temporales para su ejercicio, sin que por ello deduzcan los jueces en los pleitos ante ellos presentados que dichos plazos sean meramente «posibilidades» o «babilitaciones», sino períodos de tiempo en los cuales deben hacerse efectivos tales derechos, so pena de la caducidad o prescripción de los mismos ${ }^{25}$.

3. Conviene también efectuar ciertas precisiones respecto al supuesto del Derecho comparado y, más en concreto, en lo que afecta al caso italiano. Cierto que se produjo la escisión entre el PSIUP y el PSI y cierto que se transformaron en dos grupos diversos. Pero frente a esto podría objetarse que nó sólo la normativa a aplicar es distinta en nuestro caso, sino que la misma doctrina italiana no es unánime al enjuiciar la validez de este supuesto. Así, frente a las afirmaciones que antes recogíamos de Rescigno están las que hace Savignano cuando, al enfrentarse al problema, señala que «da quanto si è innanzi detto sul collegamento intercorrente tra gruppi politici e gruppi parlamentari, non pare dubbio che si sia intesso stabilire, sia pure implicitamente il principio opposto, di modo che non puo ammettersi, anche allo scopo di impedire il prodursi di eventuali coalizioni di soli deputati, la formazione di gruppi parlamentari se non all'inizio della legislatura» ${ }^{26}$. Y entiende que ello es también aplicable al supuesto del último apartado del artículo 26 del Reglamento italiano (partidos políticos de ámbito estatal con un número mínimo de escaños).

Por todo ello, la validez del análisis comparatista, dada la diversidad y disparidad de puntos de referencia, es, en este punto, de dudosa utilidad.

4. Más claro está, a nuestro juicio, el tema de los precedentes parlamentarios. Se ha alegado por algún autor ${ }^{27}$ la existencia de un supuesto de creación de grupos durante la legislatura, señalándose a estos efectos el caso del Grupo Vasco-Catalán, que posteriormente daría lugar a la creación de dos

${ }^{24}$ Tal y como parece colegir Linde Paniagua en el artículo antes citado.

${ }^{25}$ Vistas las características de una y otra institución, nos inclinaríamos a señalar que en el presente caso, y suponiendo un ejercicio extemporáneo del derecho, lo que se habría producido es su caducidad. Véase a este respecto L. Díez-Picazo y A. Gullón, Sistema..., cit., págs. 436 y 448.

${ }^{26}$ Cfr. Savignano, I Gruppi..., cit., pág. 59.

${ }^{27}$ Véase Torres del Moral, art. cit. 
grupos diferentes: la Minoría Catalana y el Grupo Vasco (PNV). A mi juicio, esto es totalmente inexacto y hay que hablar de falso precedente. Vamos a ver por qué.

En primer lugar hay que señalar que no se produjo una escisión reglamentaria stricto sensu, sino una adecuación de los grupos parlamentarios a la entrada en vigor del Reglamento Provisional del Congreso, que supuso a este respecto una variación fundamental.

En efecto, las Normas Provisionales de la Presidencia de las Cortes ${ }^{28}$ preveían, en su artículo 13, que, «una vez constituidas internamente las Cámaras, se procederá en cada una de ellas a la determinación del número mínimo de diputados o senadores o de los requisitos que las distintas formaciones políticas han de reunir para integrar un grupo parlamentario».

De acuerdo con este precepto, el Partido Socialista solicitó, y fue aceptado por la Cámara, que dicho número mínimo fuera de quince diputados ${ }^{29}$.

Este número mínimo, sin ninguna precisión complementaria, obligó a los representantes de las formaciones políticas catalanas y del PNV a formar un grupo parlamentario conjunto Vasco-Catalán. Sin embargo, la aprobación del Reglamento, en su versión originaria del artículo 20.1, dulcificaba la normativa para los partidos de ámbito regional al permitir formar grupo parlamentario propio a las formaciones políticas que hubiesen concurrido como tales a las elecciones y obtenido, al menos, un 20 por 100 de los escaños en el conjunto de las circunscripciones en que hubiesen presentado candidaturas ${ }^{30}$. De esta manera, la conformación de dos grupos parlamentarios distintos se hizo de acuerdo con el Reglamento Provisional ab origine. Además, y por si los datos anteriores no fuesen suficientemente convincentes, cabe alegar que la Disposición transitoria segunda del RPC, frente a la regla general establecida en su apartado 1, de que «los grupos parlamentarios constituidos antes de la aprobación del presente Reglamento continuarán como tales, sin necesidad de acto alguno de confirmación», precisa un supuesto específico aplicable concretamente al caso que nos ocupa en su apartado 2, que reza:

«Durante la presente legislatura se entenderá aplicable lo dispuesto en el número 5 del artículo 20, salvo lo reconocido a las formaciones políticas de ámbito territorial por el número 1 del mismo artículo, que deberá ejercerse en el plazo de cinco días a partir de la entrada en vigor de este Reglamento.»

Creemos que la propia claridad de la literalidad de esta transitoria, así como el desarrollo de los hechos que hemos detallado, nos exime de explicar con más detalle nuestra afirmación de que no hay precedente alguno del supuesto que estamos estudiando en este artículo y de que, por ende, las afirmaciones en contrario son inexactas.

Todas estas razones apuntadas convergen en el sentido de señalar el carácter perentorio del plazo que se marca en el RPC. Empero, podemos pregun-

${ }^{28}$ BOC, núm. 1.583, 11 de julio de 1977.

29 Véase Diario de Sesiones, núm. 2, 14 de julio de 1972, pág. 34.

${ }^{30}$ Véase nota 8. 
tarnos la razón de la brevedad de ese término. Dos son, a nuestro juicio, las causas que podrían explicarlo.

De una parte, y en esto coincide la práctica unanimidad de los autores, las necesidades de funcionalidad de la Cámara, uno de los polos de la tensión que anteriormente habíamos señalado, exigen una pronta constitución de los grupos al efecto de diseñar el módulo de proporcionalidad, la designación de miembros en las Comisiones, etc. ${ }^{31}$.

De otra parte, existe una razón mucho más de fondo, que enlaza con alguno de los temas ya tratados y con varios de los que expondremos después. Se trata, ni más ni menos, del intento de que los avatares en el seno de los partidos políticos no se transpongan -o al menos se extrapolen lo menos posibleal ámbito de los grupos parlamentarios. Efectivamente, al señalar un plazo brave a la constitución de los grupos parlamentarios, se intenta que éstos reflejen tal cual la estructura política emanada de la voluntad popular salida de las elecciones. En este sentido señalaba el senador italiano Januzzi, en una discusión parlamentaria, que «l'eccesivo numero dei Gruppi, ove dovese malauguratamente corrispondesse al frazionamento delle forze politiche espresso col suffragio sarebbe una dura e non modificabile realtà. Ma se non se corrispondesse alla configurazione delle forze politiche del Paese, quale si riveló al momento del suffragio elettorale, evidentemente il frazionamento del Parlamento in vari Gruppi, sottogroppi, piccoli Gruppi apparirebbe ingiustificato e non avrebbe como effetto che indebolire l'istituto parlamentare di fronte ad un corpo elettorale che tale effetto non avrebbe voluto» ${ }^{32}$.

Hoy día, los partidos políticos son en su mayoría lo que la doctrina americana denomina como catch-all parties o partidos de amplio espectro, que recogen en su seno grupos, tendencias y líneas a veces muy diversas. Es lógico suponer que de ello pueden derivarse discrepancias, pugnas y conflictos (incluso graves algunos de ellos), en donde pueden darse, y de hecho se darán siempre, mayorías y minorías en el seno del propio partido. Pues bien: poniendo un límite temporal tan estricto a la constitución de grupos parlamentarios, se intenta, a nuestro juicio, que estas pugnas internas salten lo menos posible dentro del ámbito parlamentario y se solventen por el juego democrático interno de corrientes y grupos en el propio seno de los partidos ${ }^{33}$.

Por último, y aunque no sea ciertamente el elemento determinante, no hay que olvidar que la infraestructura material y económica que conlleva un grupo ${ }^{34}$ hace aconsejable la estabilidad de los grupos en tanto que tales. Al menos en la práctica parlamentaria española, las subvenciones se hacen atendiendo a dos módulos. Uno de ellos está en función del número de diputados pertenecientes al grupo. El otro, en cambio, es un canon fijo e igual por grupo. De esta manera, y si otra cosa no se dispusiese en cuanto a la imposibilidad de

31 Véase Savignano, art. cit., págs. 59 y 125, y Waline, «Les Groupes...», cit., página 1193.

${ }^{32}$ Véase su brillante intervención en Savignano, cit., pág. 125.

${ }^{33}$ En sentido concorde véase la muy acertada interpretación de Rossano en Partiti..., cit., págs. 249 y sigs. $\mathrm{y}$ sigs.

Cf. att. 21 del Reglamento Provisional del Congreso y Rossano, ob. cit., págs. 256 
constituir grupos parlamentarios en el transcurso de la legislatura, la creación de los mismos podría convertirse en un medio de financiación inicial de los sectores desgajados de los grupos parlamentarios o partidos políticos. No se nos escapa, no obstante, que la cantidad asignada como canon fijo a los grupos parlamentarios hace inviable pensar que el nuevo partido emergente viviese sólo de esta asignación, pero sí que podría ser una aportación inicial importante en la fase fundacional de un partido político.

\section{VERTIENTE POLITICA DEL PROBLEMA}

Dados los datos que antes he expuesto, veo llegado el momento de conducir las derivaciones lógicas de este estudio, entrando en aquellos presupuestos histórico-políticos que fundamentan hoy día la relación básica subyacente que existe entre el diputado y el grupo parlamentario.

En efecto, es de todo punto necesario un análisis histórico, porque, como señala García Pelayo, «... no se puede aplicar al mundo del presente una imagen de la constitución surgida en tiempos en los que la interacción entre el Estado y los componentes de la sociedad era menor y más simple que en la actualidad» ${ }^{35}$. Aun no queriendo hacer aquí una completa teoría de la representación - tema que nos desbordaría ampliamente-, no es menos cierto que una referencia, siquiera sea sumaria, puede llevarnos a aclarar muchas cosas.

En primer lugar, no estamos hoy, parece claro, ante el Estado liberal representativo del XIX, que, fuese o no un modelo ideal o descriptivo más bien que real, se fundamentaba en dos premisas básicas: la unidad $e$ indivisibilidad de la nación y la estructura individualista de la sociedad ${ }^{36}$.

Hoy día este esquema que servía - no hay por qué ocultarlo- a unos intereses políticos muy claros, ha quedado superado y no es válido para explicar sin mayores precisiones el fenómeno del mandato parlamentario. Nuestra sociedad y nuestro Estado, ese Verbändestaat del que hablaba la doctrina alemana, ha visto surgir entre individuo uti singuli y Estado una serie de organismos y cuerpos intermedios que hacen de la sociedad una interrelación y entramado de grupos y conjuntos que buscan obtener sus respectivos objetivos sectoriales.

Es en este marco donde hay que entender el fenómeno de la aparición y preponderancia de los partidos políticos - cuya bibliografía obviamos aquí por ser suficientemente conocida - en la escena parlamentaria.

Con escasas fisuras, la doctrina ha hablado de intermediación para referirse a la función que cumplen los mismos entre electorado y parlamento ${ }^{37}$.

${ }^{35}$ Las transformaciones..., cit., pág. 130.

36 A este respecto es de suma utilidad el magnífico análisis del propio García Pelayo en su obra citada, págs. 110 y sigs., y también, para el caso italiano, y más en concreto referido a la estructura parlamentaria, el tantas veces citado Savignano, págs. 18 y sigs.

37 Así, por ejemplo, García Pelayo, op. cit., pág. 116: «... la sociedad del presente es una sociedad organizacional, una sociedad estructurada en organizaciones en la que ni los objetivos individuales ni los colectivos pueden conseguirse más que a través de las orga- 
Ante esta situación de hecho, producida por igual, aunque no sincrónicamente, en todos los países democráticos, se preguntaba con agudeza Waline si ello era compatible con el mandato representativo ${ }^{38}$.

En efecto, cuando se invoca hoy día el mandato representativo como deus ex macbina que facilita cualquier tipo de actitud a los diputados $\mathrm{y}$, aún más, cuando se quiere fundamentar el derecho a la constitución de grupos parlamentarios en el mandato representativo ${ }^{39}$, se están equivocando, a nuestro juicio, los verdaderos presupuestos del mismo. Expondremos por ello el sentido actual de las relaciones entre grupo parlamentario y diputado individual en dos fases. En una primera explicaremos el posicionamiento que adopta el Reglamento Provisional del Congreso a este respecto. En la segunda señalaremos el perfl actual del mandato representativo y su margen de juego, intentando deshacer algunos equívocos.

\section{a) Diputado individual y cambios de grupos}

Ya hemos visto con anterioridad que la situación del diputado individual en la Cámara se halla muy ligada al fenómeno electoral. De esta manera, las elecciones no son ya unas elecciones entre notables o figuras aisladas consideradas en su singularidad, sino, en su mayor parte, unas elecciones celebradas entre listas de partidos políticos que intentan atraerse al electorado con sus programas, de modo y manera que el cuerpo electoral viene a pronunciarse generalmente en la lucha de los partidos y el voto formulado en favor del candidato singular tiene por lo general valor secundario ${ }^{40}$.

Estas tendencias, lejos de ser meramente doctrinales, se expresan y plasman hoy día en algunos textos constitucionales modernos. Así, por ejemplo, la Constitución portuguesa de 2 de abril de 1976 dispone, en su artículo 163:

«1. Perderán su mandato los diputados que (...)

c) Se inscriban en un partido distinto de aquel por el cual se hayan presentado a las elecciones (...).»

Texto de indudable trascendencia y que debe ser valorado en sus justos términos.

nizaciones...»; se da así una «... mediación y frecuente mediatización de los partidos...». En el mismo sentido, Mortati, Istituzioni..., cit., pág. 488: «Si è visto come il sorgere dei partiti abbia complicato il rapporto rappresentativo, poichè ha inserito un organo intermedio tra il popolo ed i suoi rappresentanti.» También afín a estos planteamientos, Rossano, Partiti..., cit., pág. 259.

${ }_{38}$ «En realité, sur le plan des principes, on peut se demander si cette existence ne se trouve pas en contradiction avec la nottion même de démocratie représentative. En effet, un système politique qui, par suite de la proclamation de la souveraineté nationale, admet que l'ensemble des représentants élus exprime la volonté de la nation que chaque députe concourt à la représentation de la Nation tout entière et qu'il doit pouvoir exprimer librement son opinion, ne devrait-il pas nécessairement exclure la possibilité de tout groupement au sein des Assemblées?» (op. cit., pág. 1171).

${ }^{39}$ Véase Linde Paniagua, art. cit.

40 En sentido concordante Rossano, op. cit., pág. 228. 
No obstante, esta solución está claro que no es extrapolable al ordenamiento jurídico-reglamentario español. ¿Cómo se canalizan entonces las posibles discrepancias o escisiones habidas en los partidos políticos representados en grupos parlamentarios? $\mathrm{O}$, lo que es lo mismo, ¿qué margen de actuación le queda al diputado que abandona un grupo parlamentario?

De lege data, la solución prevista en el RPC se articulaba por dos vías:

1. La primera se halla recogida en el segundo inciso del apartado 6 del artículo 20. En dicho precepto se estipula:

«El diputado que, por cualquier causa, dejare de pertenecer a un grupo parlamentario, quedará automáticamente incorporado, durante el período de sesiones en que se produzca el supuesto, al Grupo Mixto. Su presidente lo comunicará a la Mesa del Congreso.»

De modo y manera que el cese en un grupo parlamentario, «por cualquier causa», no implica la pérdida del escaño (la doctrina ha sido unánime en rechazar la validez de las renuncias en blanco firmadas por los diputados) ${ }^{41}$, pero sí el paso «automáticamente» al Grupo Mixto, caso de que su abandono del grupo se produzca durante un período de sesiones ${ }^{42}$.

2. La segunda vía es lógica consecuencia de la primera. Estemos o no de acuerdo a nivel de política legislativa con este supuesto, que por cierto es uno de los más típicos del parlamentarismo (recordemos que Churchill cruzó más de una vez los bancos de los Comunes), lo cierto es que el diputado que abandona un grupo no se halla obligado a permanecer ad calendas graecas en el Grupo Mixto, sino sólo y únicamente «durante el período de sesiones en que se produzca el supuesto» (art. 2.6, segundo párrafo).

Consecuentemente con ello, dispone el apartado 4 del tantas veces citado artículo 20 del RPC:

«Podrán incorporarse a los diversos grupos creados, en calidad de miembros o adheridos, los diputados que expresen su voluntad de hacerlo así mediante escrito dirigido a la Presidencia de la Cámara. Este escrito deberá llevar el visto bueno del presidente o portavoz del grupo de que se trate.»

Este artículo viene a defender el mandato representativo en su sentido decimonónico y la institución de lo que en Italia se denominó «transformismo» ${ }^{43}$, y entre nosotros se ha vulgarizado recientemente con la figura del llamado «diputado tránsfuga». Fenómeno este de la reacomodación de los dipu-

${ }^{41}$ Como muestras véase Mortati, op. cit., pág. 490, y Torres del Moral, «Los grupos...», cit., pág. 57. A conclusiones análogas se llegó en el curso celebrado en la Universidad Internacional Menéndez Pelayo el verano de 1981, y que versó sobre los «Problemas actuales de la institución parlamentaria».

${ }^{42}$ No así en los períodos intersesiones, en los que la práctica parlamentaria permite el trasvase directo de diputados de un grupo a otros sin «parada intermedia» en el Grupo Mixto.

${ }^{43}$ Véase Savignano, op. cit., pág. 15. 
tados en los diversos grupos bastante corriente en las últimas fases de las diferentes legislaturas.

Las soluciones jurídicas, pues, que contemplaba el RPC protegían adecuadamente al diputado en el caso de enfrentamiento con su propio grupo, sin que se viese arrojado del escaño o condenado o atado a estar en su grupo contra su voluntad.

\section{b) El mandato representativo. El artículo 67.2 de la Constitución}

Señalábamos antes que hay quien ha pretendido fundamentar el derecho a constituir grupos parlamentarios durante la legislatura en el precepto constitucional del artículo 67.2, que dispone:

«Los miembros de las Cortes Generales no estarán ligados por mandato imperativo.»

Esta afirmación demuestra, a nuestro juicio, una observación apresurada y errónea tanto del mandato representativo como del influjo del juego de los partidos respecto a él.

De una parte hay quien, como Ferri, se ha planteado para el caso italiano este tema, y lo ha resuelto negativamente al interpretar el artículo 67 de la Constitución italiana similar al nuestro: «Nel senso che il solo divieto ivi contenuto è di rappresentare entità diverse dalla nazione, cioè territorialmente circoscritte, mentre tale non sarebbe il partito che, in quanto esprime indirizzi politici e perciò generali, rappresenta la nazione nella configurazione politica da essa assunta» ${ }^{44}$.

Aun cuando se pueda discrepar de las conclusiones rigurosas o extremistas que pudieran sacarse de dicha interpretación, no es menos cierto que, además de la necesaria perspectiva histórica que hemos reivindicado a lo largo del presente artículo, es de todo punto imprescindible una rigurosa interpretación jurídico-sistemática del precepto constitucional, puesto que la Carta Máxima, no lo olvidemos, es un corpus jurídico y como tal no una mera agregación inconexa de preceptos, sino algo que debe interpretarse de forma armónica y coordinada en sus diversas disposiciones.

Ello viene a cuento de que quien aisladamente reivindica el tenor del artículo 67.2 olvida con frecuencia la presencia en la Constitución de una norma básica que aparece en el mismo pórtico, que es su título preliminar. Nos estamos refiriendo, ocioso es decirlo, al artículo 6. En efecto, este artículo dispone en su inciso primero:

«Los partidos políticos expresan el pluralismo político, concurren a la formación y manifestación de la voluntad popular. y son instrumentos fundamentales para la participación política.»

Obviamente, la formación de la voluntad popular tiene su máxima expresión en los períodos electorales, y obviamente también la «manifestación de

${ }^{4}$ Cfr. Mortati, op. cit., pág. 489. 
la voluntad popular» y «la participación política» alcanzan sus momentos más relevantes (aunque, claro está, no sean los únicos) en el Parlamento y en las diversas Cámaras. Si, como antes hemos tenido oportunidad de ver, los partidos políticos se articulan esencialmente en las Asambleas legislativas a través de los grupos parlamentarios, no nos queda más remedio que concluir que existe una indudable base constitucional de la actividad de los grupos parlamentarios y, más en concreto, de sus tareas de fijación, filtro y selección de las posturas políticas a adoptar ante las cuestiones planteadas ${ }^{45}$.

Todavía se podría argumentar que los grupos parlamentarios son colectivos compuestos de personas físicas - los parlamentarios-, que, como tales, contribuyen a la fijación de sus posiciones. Por ende, el principio democrático exige que, una vez defendidas las diversas tesis y democráticamente decididas las cuestiones, las decisiones de la mayoría predominan sobre las minorías.

Por todo esto, el sentido del mandato representativo no puede encontrarse hoy día en formulaciones históricas originales, sino en su adecuación al momento presente. La validez y vigencia actuales de este principio se justifican, a nuestro juicio, en ser el último baluarte de defensa del diputado individual frente a la tiranía del grupo. Por ello nos parece extremadamente correcta la tesis de Mortati cuando indica que «tuttavía il principio predetto (el representativo) deve ritenersi mantenuto, in quanto è assicurata la libertà del parlamentare di sottrarsi in ogni momento a tale disciplina affrontando le sanzione interna inflitte dal partito che culminano nell'espulsione, o usando della facoltà di lasciarlo anche senza aderire ad un otro partito (nel qual caso si rende posibile l'iscrizione a un gruppo parlamentare "misto')..." ${ }^{46}$.

De modo y manera que el mandato representativo no es, no debe ser, una patente de corso para «actuar por libre» (ya que en una sociedad actual posturas como la de Condorcet son inviables), sino un refugio último de la libertad individual y política del diputado acosado por las presiones excesivas de su grupo/partido.

De otra parte, es constatable el asombro que causa intentar justificar la constitución de grupos a mitad de la legislatura en el mandato representativo cuando, como hemos tenido ocasión de ver con anterioridad en la sutil exposición de Waline, ambas instituciones son absolutamente contradictorias. Podría intentar justificarse la actuación incontrolada o personal de un diputado en la institución del mandato representativo, pero nunca su deseo de escindirse de un grupo parlamentario para entrar a formar parte de otro de nueva creación.

${ }^{45}$ En sentido concordante véase Mortati, Istituzioni..., cit., pág. 489, que, después de señalar la institucionalización del vínculo entre los miembros del Parlamento y del partido, concluye afirmando que «non è dubbio che l'inserzione dei parlamentari nei partiti e nei gruppi parlamentari che ne sono espressione importa l'osservanza di una disciplina che limita la autonomia del singolo in varie direzione...». También en la vía de indicar la titularidad del partido a la hora de designar los fines a alcanzar frente al grupo parlamentario en su conjunto y a los diputados en particular, véase Savignano, op. cit., páginas $206 \mathrm{y}$ sigs.

46 Mortati, op. cit., pág. 489. 


\section{ULTIMAS OBSERVACIONES}

De todo lo anteriormente expuesto parece desprenderse, a nuestro juicio con nitidez, la corrección de la postura de la Presidencia del Congreso denegando, en función de la normativa aplicable, en este caso el Reglamento Provisional del Congreso, la posibilidad de constituir grupos en el transcurso de la legislatura. Razones de índole jurídica especialmente, pero también sólidos motivos de lógica política de las instituciones, avalan dicha decisión.

$\mathrm{Y}$ es que el problema que plantean hoy día los grupos parlamentarios en las Asambleas legislativas está correctamente formulado por Waline: «Aussi grands que puissent paraître les inconvenients au regard des avantages, il faut se rendre à l'évidence: les groupes politiques constituent l'un des rouages de notre système parlementaire et le mouvement qui a aimené leur promotion est irréversible. A l'instauration d'un 'système des partis' a correspondu l'instauration d'un véritable 'système des groupes' au sein des Assemblées. Le problème est, desormais, d'aménager ce système des groupes pour le mettre au service de notre régime parlementaire» ${ }^{47}$.

No queremos terminar este trabajo sin señalar lo incorrecto de una posición bastante en boga en la doctrina actual. La intermediación de los partidos no es per se perjuidicial para la vida política y parlamentaria, lo perturbador son sus disfunciones. La intermediación de los partidos, lejos de ser un colchón obstaculizador, como decía la ideología liberal, está — si se despliega correctamente- dirigida a potenciar la eficacia de la acción de la sociedad sobre el Estado, a actualizar el diálogo entre electores y elegidos, como dice Mortati ${ }^{48}$, diálogo que se hace tanto más difícil cuanto más se amplía la masa electoral.

En cualquier caso, lo que parece cierto es que la decisión de la Presidencia fue especialmente acertada, porque la configuración jurídico-reglamentaria de ese momento no permitía la creación de grupos parlamentarios fuera del plazo predeterminado, $y$, si la seguridad y la certeza jurídicas son dos de los pilares esenciales del Estado de Derecho, es preferible que el Estado cambie sus normas a que las viole, porque el Estado es el primer súbdito del Derecho ${ }^{49}$.

47 Waline, op. cit., pág. 1237.

${ }^{43}$ Op. cit., pág. 488 .

${ }^{49}$ Véase Elías Díaz, Sociología y filosofía del Derecho, Madrid, 1971, pág. 44. 